\title{
ДИЗАЙН И АРХИТЕКТУРА КАК ИНСТРУМЕНТ ПОВЕСТВОВАНИЯ В ИГРОВОМ ВИРТУАЛЬНОМ МИРЕ.
}

\author{
Ларицкая Мария Германовна \\ Аспирант, \\ Московская художественно-промышленная академия \\ имени С. Г. Строганова
}

\begin{abstract}
Аннотация. В данной статье изучаются роль и степень влияния дизайна и архитектуры на повествование в видеоиграх. Это важно для большего понимания вопроса «чем является нарративный дизайн и какое воплощение он может иметь в играх». Для этого рассматривается три проекта, совершенно по-разному использующие окружение. Данный подход позволяет выявить ценность дизайна архитектуры как визуального языка повествования.

В результате автор приходит к мысли, что окружение не только служит инструментом погружения игрока в созданный виртуальный мир, но и является выразительным средством. Окружение может в разной степени опираться на исторические, мифические и другие источники, позволяя ему служить для аллегорического усиления эмоций и событий в повествовании.

Annotation. The article examines the role and degree of design and architecture on videogame story. It is important to better understand the question «What is a narrative design, and how can it be implemented in games». For this purpose author explores three projects that use enviroment in different ways. This approach allows to find out importance of architectural design as a visual language for storytelling.

Author concludes that environment is not only a way of immersing the player to a virtual world, but may act as expressive means. Environment can in varying degree be based on historical, mythical or other sources, allowing it to serve to allegorically reinforce emotions and events in a narrative.

Ключевые слова: Кредо Ассасина, Сублюструм, Стенли парабл, нарративный дизайн, повествование, окружение, инструмент, архитектура, дизайн, рассказчик, офис, игры.

Key words: Assassin's Creed, Sublustrum, The Stanley Parable, enviroment storytelling, architecture, design, visual language, videogame, narrative design.
\end{abstract}

\section{Вступление}

Ни одна видеоигра не обходится без мира, в котором происходят ее события. Даже если речь идет о проекте без какого-либо сюжета, или персонажей, как таковых, перед игроком предстает некий «мир», со своими правилами, законами и образами. Мир может состоять из различных элементов - фантастических и довольно привычных нам. Окружение может иметь, как природные, так рукотворные формы. Ко вторым относится и архитектура, ведь она - одно из наиболее ярких проявлений интеллектуальной деятельности, быта человека.

Для наглядности, хоть и довольно поверхностно, в рамках данной статьи, разберем некоторые два игровых проекта, в которых окружение играет разную роль в повествовании.

\section{Основное содержание}

Виртуальный мир, реальный или фантастический, требует тщательной проработки деталей как для достижения необходимого уровня правдоподобия так и раскрытия художественно замысла. Целенаправленное цитирование исторических событий, пусть и с добавлением фантастических элементов, предполагает изучение и внедрение конкретных черт, характеризующих выбранную эпоху. Серия игр Assassin’s Сreed является наглядным примером особо внимательного отношения к воссозданию исторического окружения. Каждая игра серии посвящена отдельной эпохе, яркому историческому событию. В серии присутствует сквозной фантастический элемент, связанный с возвратом к воспоминаниям предков главного героя, от лица которых игрок и наблюдает события и участвует в них. Для примера рассмотрим игру Assassin's Creed: Unity, в которой отражены события, связанные с Великой французской революцией. Авторы провели глубокое исследование и постарались перенести игрока в Париж 18 века. В игре мы имеем возможность не только созерцать город с позиции пешехода, но и взбираться на любые вертикальные поверхности, изучая окрестности вдоль и поперек, а также заходить внутрь доступных многочисленных домов для выполнения миссий, основных и побочных, поиска предметов для коллекционирования, получения достижений, поиска коротких путей и т.д. Активное использование приемов паркура главным героем позволяет ему спокойно взбираться на балки, арки, окна, крыши любых зданий и храмов, так что игрок видит окружающий мир с разных высот и с максимальной близостью к архитектурным памятникам. Разработчики уделили огромное внимание не только детализации окружения, исторической достоверности, но и смогли добиться того, что все это происходит в открытом мире без дополнительных загрузок, обеспечивая более полное погружение в игру.

В игре мы можем увидеть такие знаменитые исторические архитектурные памятники, как Люксембургский дворец, церковь Сен-Жермен-де-Пре, Пале-Рояль, Пантеон, и конечно, здесь и Собор Парижской Богоматери, 
который настолько бережно перенесен в игру в соответствии с оригиналом(благодаря старанию Кэролин Миусс - одной из сотрудниц студии Ubisoft, которая потратила несколько лет на создание детальной модели интерьера и экстерьера собора), что после пожара 15 апреля 2019 года, даже появилась мысль использовать данные наработки для восстановления Нотр-Дама. Разумеется, подробное изучение данного храма производилось и ранее. В особенности, ученый искусствовед Эндрю Тэллон, посредством лазерного сканирования, провел глубокое исследование интерьера и экстерьера и собрал поражающее количество данных с более чем пятидесяти точек. При этом погрешность составляет не более 5 мм. Что ещё любопытно, так это то, что в 2014 году, в рамках рекламной кампании, Ubisoft выпустили Project Widow - интерактивную экскурсию по Парижу, в ходе которой можно было не только прогуляться по современному городу, но и увидеть его во времена Великой французской революции. Происходила экскурсия под руководством виртуального аудио гида, которого озвучил актер Энди Серкис. Ознакомиться с такой экскурсией лично уже не представляется возможным по прежнему адресу, но сохранились некоторые данные и обзор экскурсии от WayneDavies89 на его Youtube-канале.

Таким образом, игра способна стать хорошим инструментом сохранения и реконструкции отдельных исторических элементов, предметов, а в некоторых случаях, даже событий, если это требуется.

С точки зрения самой игры, столь детальная проработка исторических элементов позволяет игроку более полно погрузиться в события игры и отразить основную ее концепцию.

При этом стоит понимать, что игра не копирует историю полностью, в ней довольно много вольностей, трактовок и коррекций, которые искажают историю. Данные расхождения довольно неплохо разобраны в статье Юрия Кулагина «Почему не стоит изучать историю по Assassin's Creed, часть III. Париж и Лондон». Некоторые изменения были сделаны в пользу геймплея(улицы стали шире, чем в реальности, чтобы процесс преодоления препятствий и вид на улицы был более интересным), некоторые факты (например, «Бастилии показано без лишних изменений. Смущает только одно: главный герой попадает в Бастилию из-за ложного обвинения в убийстве, хотя в эту крепость обычно сажали должников и политических преступников. А для убийцы, да ещё и аристократического происхождения, власти нашли бы место пожёстче.») и характеры были изменены в пользу задуманного сюжета («По версии Unity, голоса во время суда над правителем разделились поровну, 360 на 360, после чего решающий голос в пользу гильотины отдал юрист и политик Луи Мишель Лепелетье - марионетка тамплиеров... сам Лепелетье в реальности вообще был противником смертной казни, за что его и любил простой народ»). Конечно, странно упрекать фантастическую игру, не претендующую на полное моделирование истории в недостоверности. Ведь в игре воссозданы лишь наиболее памятные символы(в том числе и архитектурные), которые отражают время и место происходящих событий.

Игра опирается на историю, но в итоге создает свой вариант художественного видения происходящих событий, включая при этом свои собственные фантастические элементы.

Теперь обратимся к играм, которые лишь частично опираются на реальность или на существующие мифы и легенды с целью формирования своего уникального мира. Например, Sublustrum. Это игра, в которой сочетаются ретрофутуризм, стимпанк и сюрреализм. Выражается это в интерьерах локаций, в использовании фотографий, видеороликов, снятых в советском антураже (подъезд дома, старый склад, вокзал, трамваи и пр.) с обработкой в стиле старой кинопленки с эффектом помех, в предметах интерьера (диван, книги, картины в позолоченных или бронзовых рамах, граммофон, вырезки из газет, напольные часы, застекленные деревянные(возможно дубовые) книжные шкафы, печатная пишущая машинка, и пр). Квартира профессора сочетает в себе коридор, зал, кабинет, оранжерею с выходом в подвал-бойлерную. Все предметы в квартире говорят об однозначности рода деятельности брата главного героя - профессора. В том что он ученый, глубоко занятый своими исследованиями, не возникает никаких сомнений. Об этом говорят не только его записи, то и дело попадающиеся нам при исследовании помещений, обилие книг, но и сама квартира, предметы интерьера, который сочетает в себе черты сталинской квартиры с точечными фрагментами модерна (дверь в кабинет профессора).

Есть здесь и чисто фантастические элементы, которые сразу бросаются в глаза и подтверждают информацию из заметок профессора - например капсула или органофон. Каждый интерактивный предмет в игре так или иначе имеет свою цель и назначение и может быть упомянут прямо или косвенно в записях:

- капсула профессора, напоминающая водолазный колокол (возможно им и является, если судить по найденным заметкам),

- органофон, сочетающий в себе черты органа и граммофона, который был сконструирован для того, чтобы подбирать частоту, необходимую для работы капсулы. 


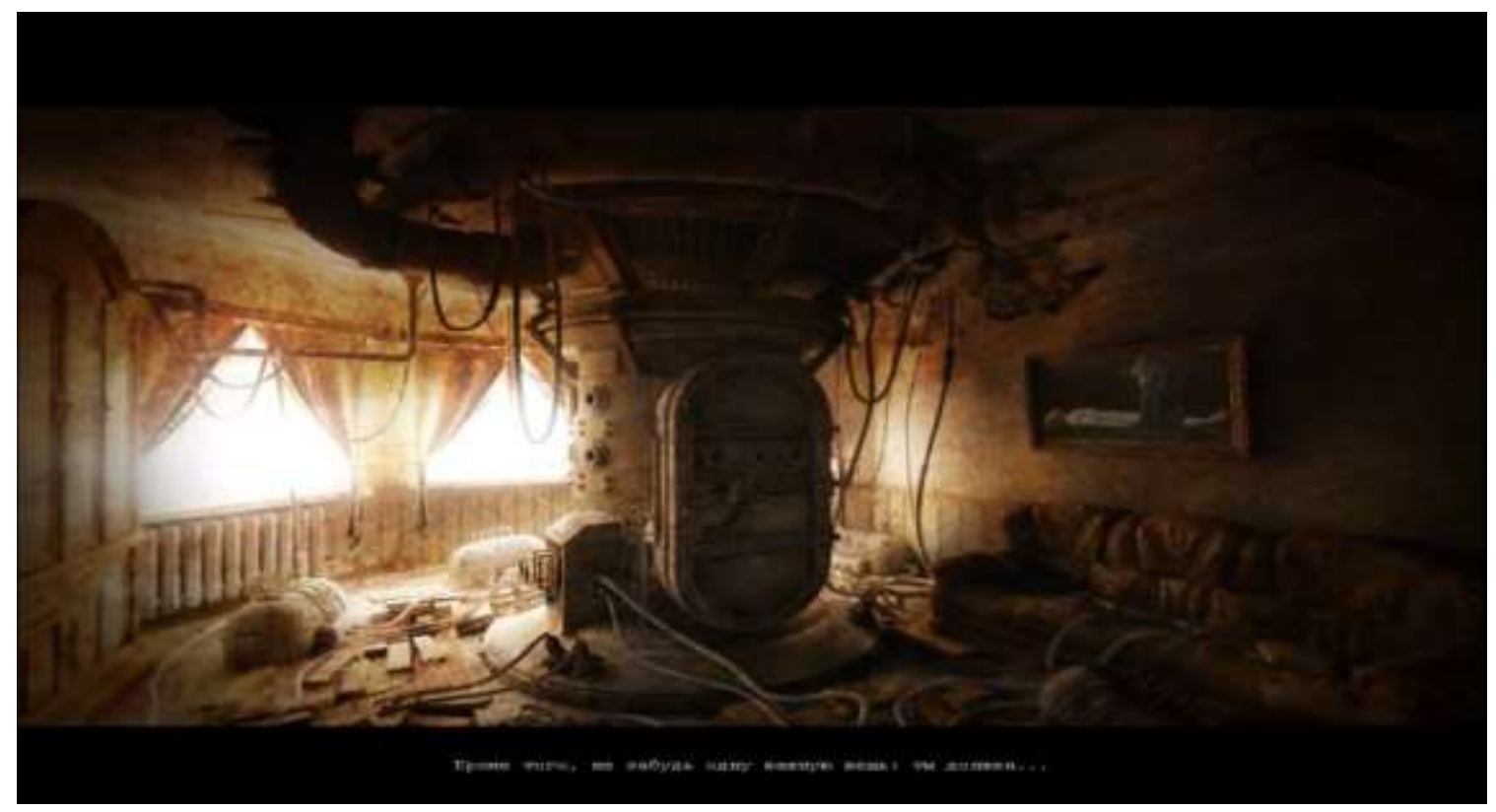

Предметов мебели в квартире профессора немного, но они выглядит добротными, крепкими и функциональными, без излишков и лишенные украшений. В центре кабинета профессора в лоджии стоит крепкий возможно дубовый письменный стол, с множеством выдвижных шкафов. Низкое деревянное кресло с прямыми подлокотниками, резными основаниями, ножками и спинкой и обитое тканью, напоминает византийский трон. Органофон - справа от входа, опутанный проводами, слева от входа - крепкие книжные полки.

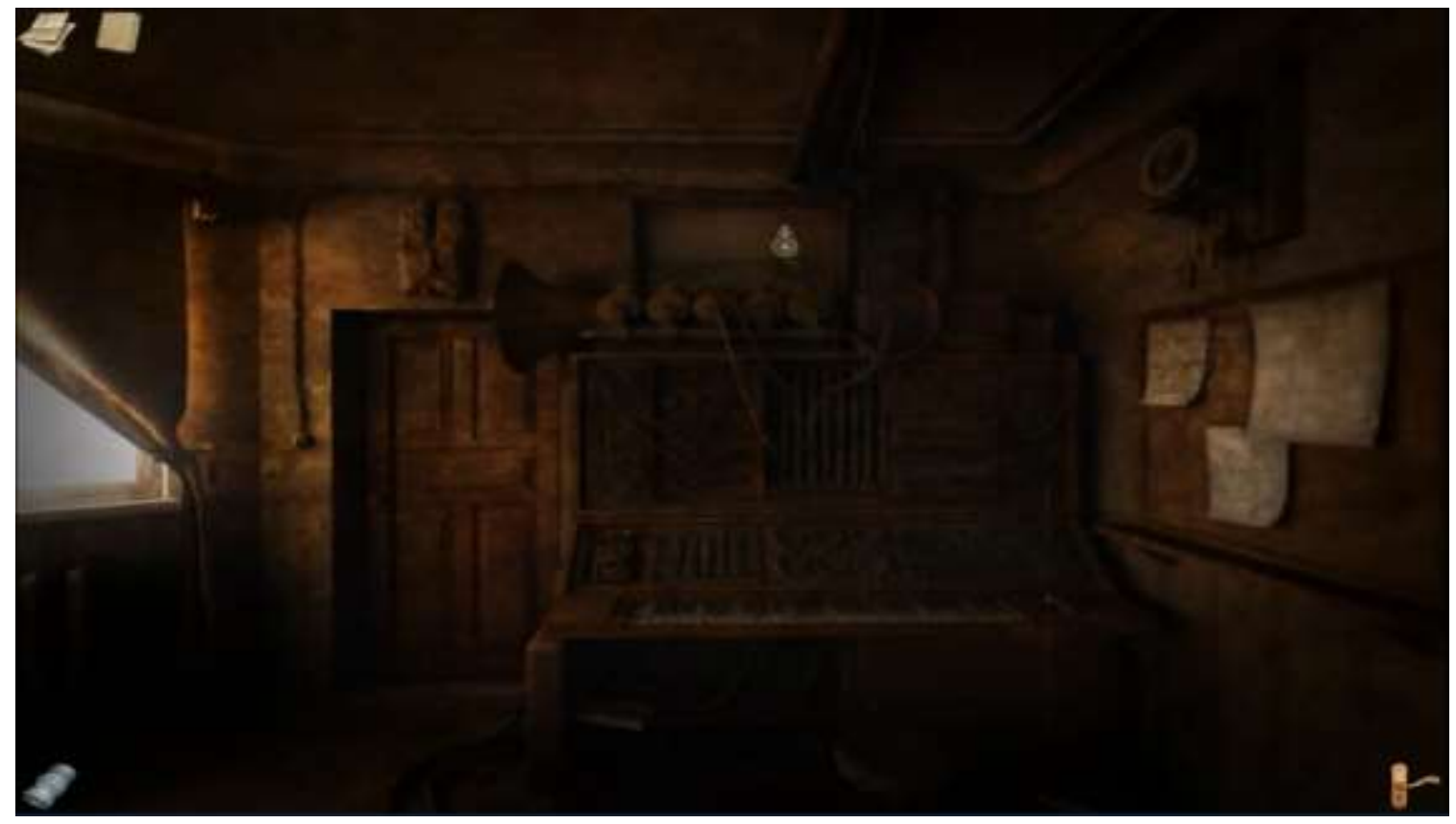

Также в записях упоминается некое путешествие и попытки достичь иных миров, в квартире профессора, можно найти книги и крайне увлеченные заметки о дольменах, снах, разбор видений, добавления исторических выписок из реальных исторических событий, исследований об опытах древних цивилизаций, которые контрастируют с дневниковыми записями профессора о работе и реальности, которые его более совершенно не интересуют и не кажутся такими важными, в отличие от его исследования. Реальность то и дело норовит нарушить планы профессора, явно намекая на то, что простая советская квартира не приспособлена к таким экспериментам (низкие и высокие частоты вызывают мигрень у соседей(некоторые из них даже стали считать что дом проклят), чрезвычайная нагрузка на сеть вызывает ее перегруз, а непредвиденные расходы постепенно истощают финансовые ресурсы и ставят под вопрос само исследование). Таким образом мы видим, насколько обычный, 
привычный нам, мир оказывается тотально не приспособлен для нужд и исследований профессора. Ему буквально приходится бороться за каждый этап исследования.

Впервые игрок слышит об ином мире, когда он только попадает в квартиру профессора и среди прочего звучит следующее описание:

«В нем можно встретить до боли знакомые образы, и в то же время пространство это глубоко чуждо человеку, что ощущается во всей его обстановке». «Мерцающие миры», в которые мы попадаем благодаря капсуле представляют собой совершенно не похожие друг на друга локации, зачастую фантастические. Например, в детских воспоминаниях о совместной поездке мы видим деревянный дом-маяк и механический цветок на смотровой, а неприятные обрывки воспоминаний вовсе лишены визуальной части. О происходящих событиях нам говорит жалобный визг больной собаки, забитой хулиганами. Мучительная атмосфера подчеркивается неприятными низкими завывающими и лязгающими звуками, а также сменой темного, тусклого цветового фильтра на мрачный кроваво-красный после смерти собаки. Сцена в пустыне выглядит как обрывок воспоминания, в который мы попадаем в момент выхода из предыдущей локации через секретный лаз и оказываемся у дольмена[1] уже в пустыне.

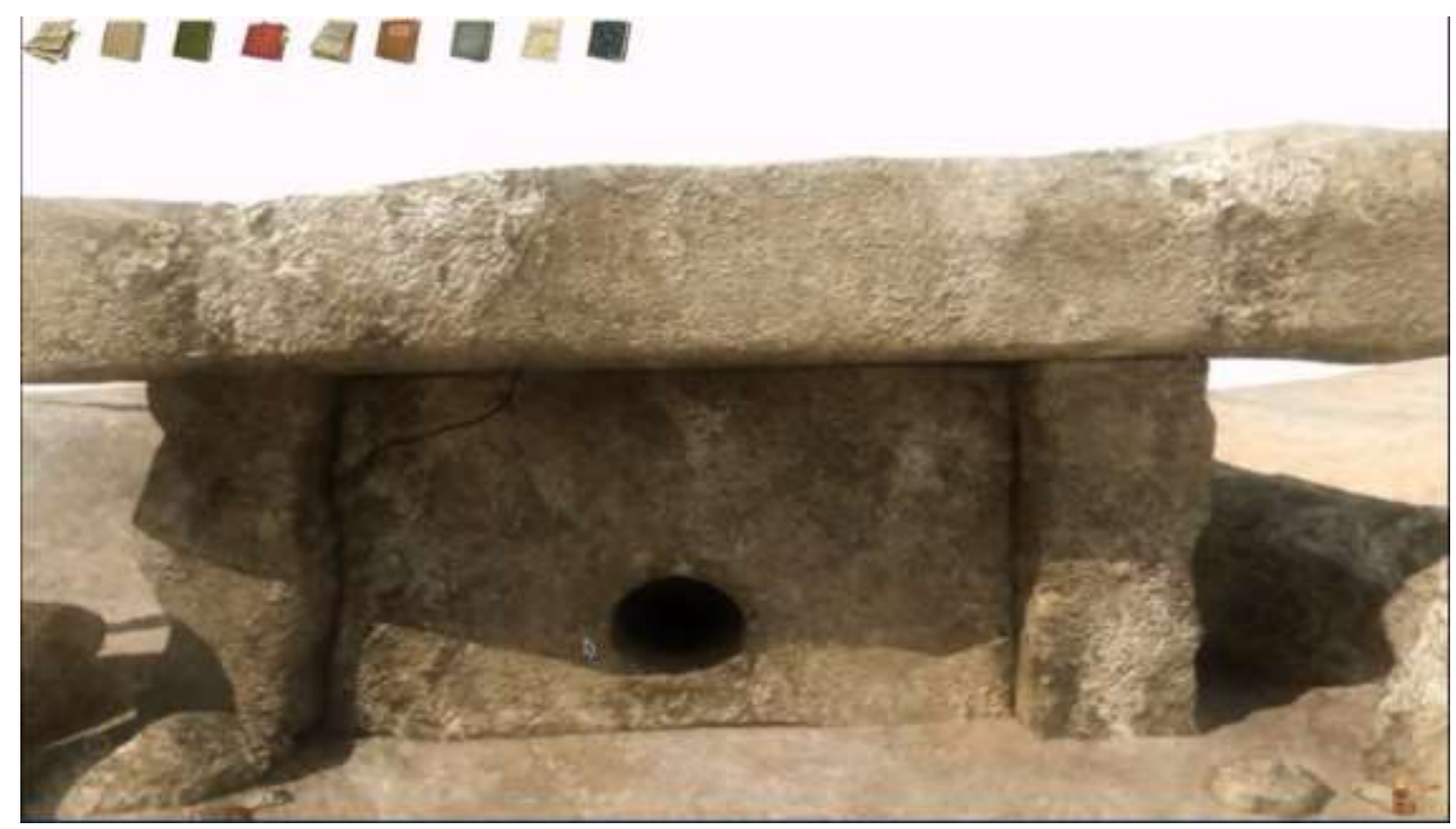

Сделав несколько шагов, мы обнаруживаем лишь кусок города, словно вырванный из своей привычной среды. Выражается это в кусках асфальта, остатках улицы, домов, одиноко стоящем трамвае и причудливо искаженных линиях передач.

1 Дольмены мыли упомянуты ранее в заметках профессора, а также игрок находит в какой-то момент книгу на данную тему. 


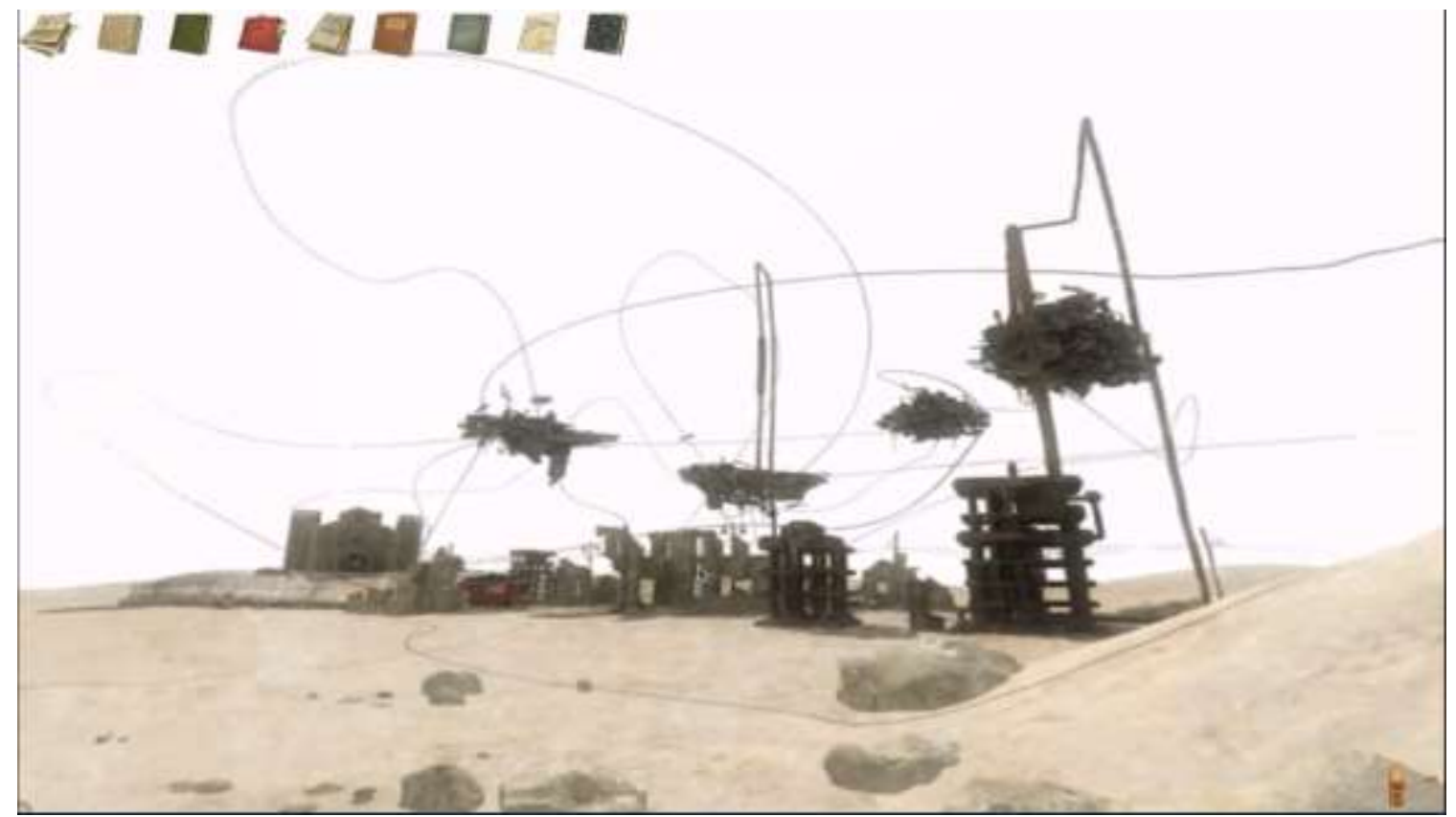

Игрока не покидает ощущение постоянного процесса распада, превалирование пустоты, отсутствия будущего и деградация в целом. Локации наглядно демонстрируют постепенную утрату воспоминаний. Об этом говорит и отсутствие некоторых частей окружения (асфальта, стен, фрагментов пола, отдельных предметов и тд).

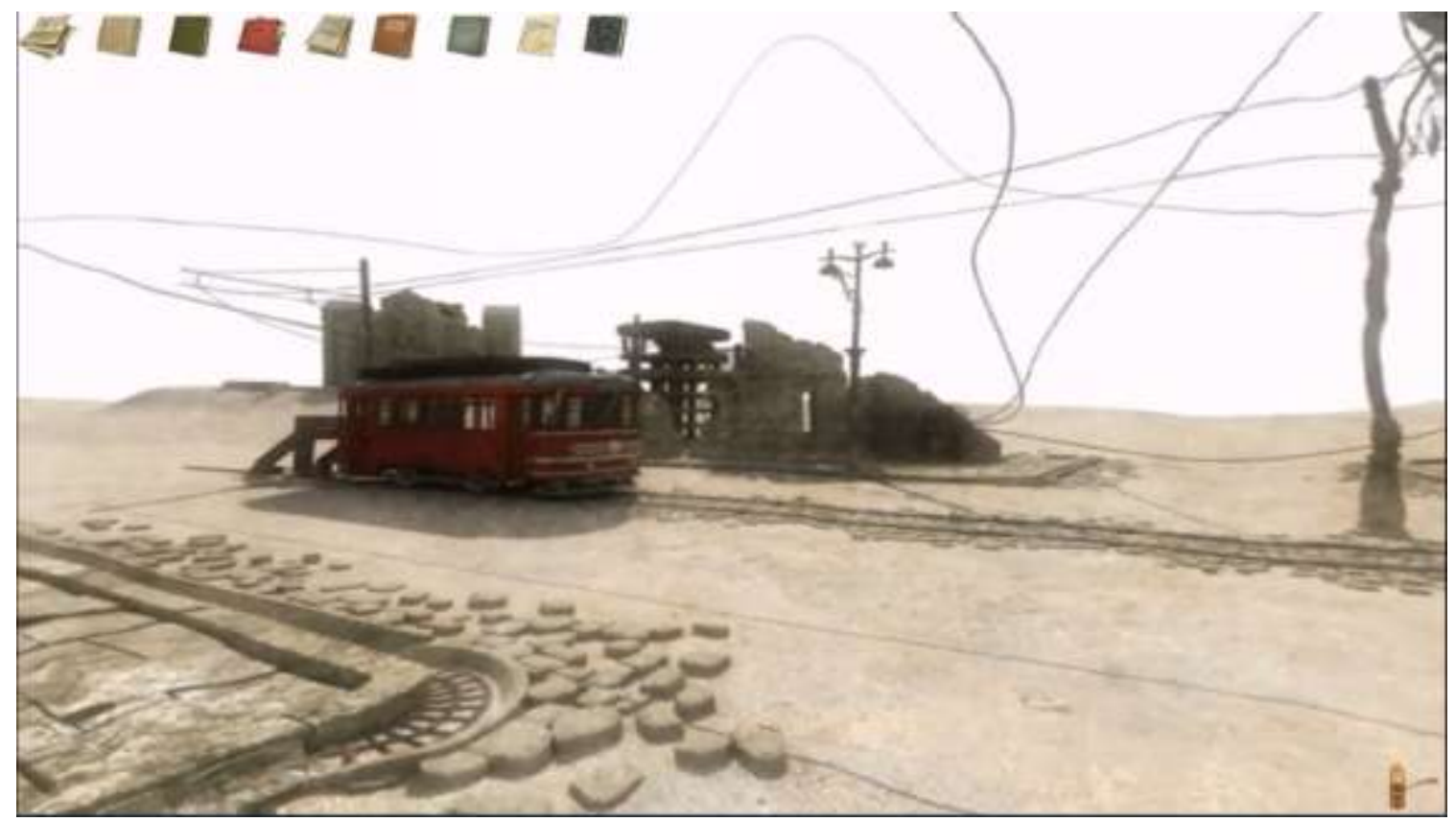

Особую роль в данном произведении играют звук и музыка(в стиле dark-ambient [2]), которые в сочетании со всеми выше упомянутыми элементами создает совершенно волшебную псевдонаучную, но очаровывающую атмосферу истории, которая повествует то ли о поисках брата в осколках его воспоминаний, то ли о последнем сне, полном сожалений о прошлом, ошибки которого уже не исправить, а светлые воспоминания - не вернуть.

Рассмотрим еще одну игру The Stanley Parable, являющуюся наглядной демонстрацией того, как окружение может быть прямым инструментом взаимодействия игры с игроком. Главным двигателем сюжета, в The Stanley Parable являются одновременно, и игрок, и рассказчик. Последний не только комментирует происходящее, подсказывает, но и указывает куда идти главному герою. Что характерно, игрок волен выбирать свой путь и в

2 Дарк-э́мбиент - Подвид эмбиента - направлениа электронной музыки, использующее в качестве вдохновения звуки окружающей среды. В отличие от обычного эмбиента стремится создать более тяжелое, давящее ощущение. 
любой момент сойти с тропы, которую приготовил для него рассказчик, активируя новые и новые варианты развития событий. Каждое новое прохождение несет непохожие друг на друга эмоции. Рассказчик по-разному реагирует на Стенли и его действия. Он может беспристрастно вести героя по линии своего рассказа, он может шутить над Стенли, откровенно глумиться над его привычным, устоявшимся образом жизни и скучной однообразной работой, состоящей в том, чтобы нажимать кнопки по указанию свыше, которые, однако, делали Стенли счастливым на протяжении многих лет. Это выражается в открытии дверей и закрытие их перед носом главного героя со словами «о, нет. Нет. Точно не направо, я ошибся!»[3], после чего несколько раз открывает и закрывает двери перед носом Стенли в противоположных частях комнаты, вынуждая игрока проходить многократно через все помещение. То рассказчик пытается вести со Стенли диалог и пытается уговорить его остаться в безопасной комнате с северным сиянием, космическими туманностями на фоне тысяч звезд: «Пожалуйста, нет, Стенли, позволь мне остаться здесь! Не забирай это у меня!»[4]

(так как из данной локации, состоящей из подсобных помещений, коридора и комнаты с видениями нельзя выйти иначе, чем «перезапуском игры», через убийство главного героя. И то счастье, которое только что, казалось бы, обрел рассказчик, исчезнет, и игра «снова начнется сначала».

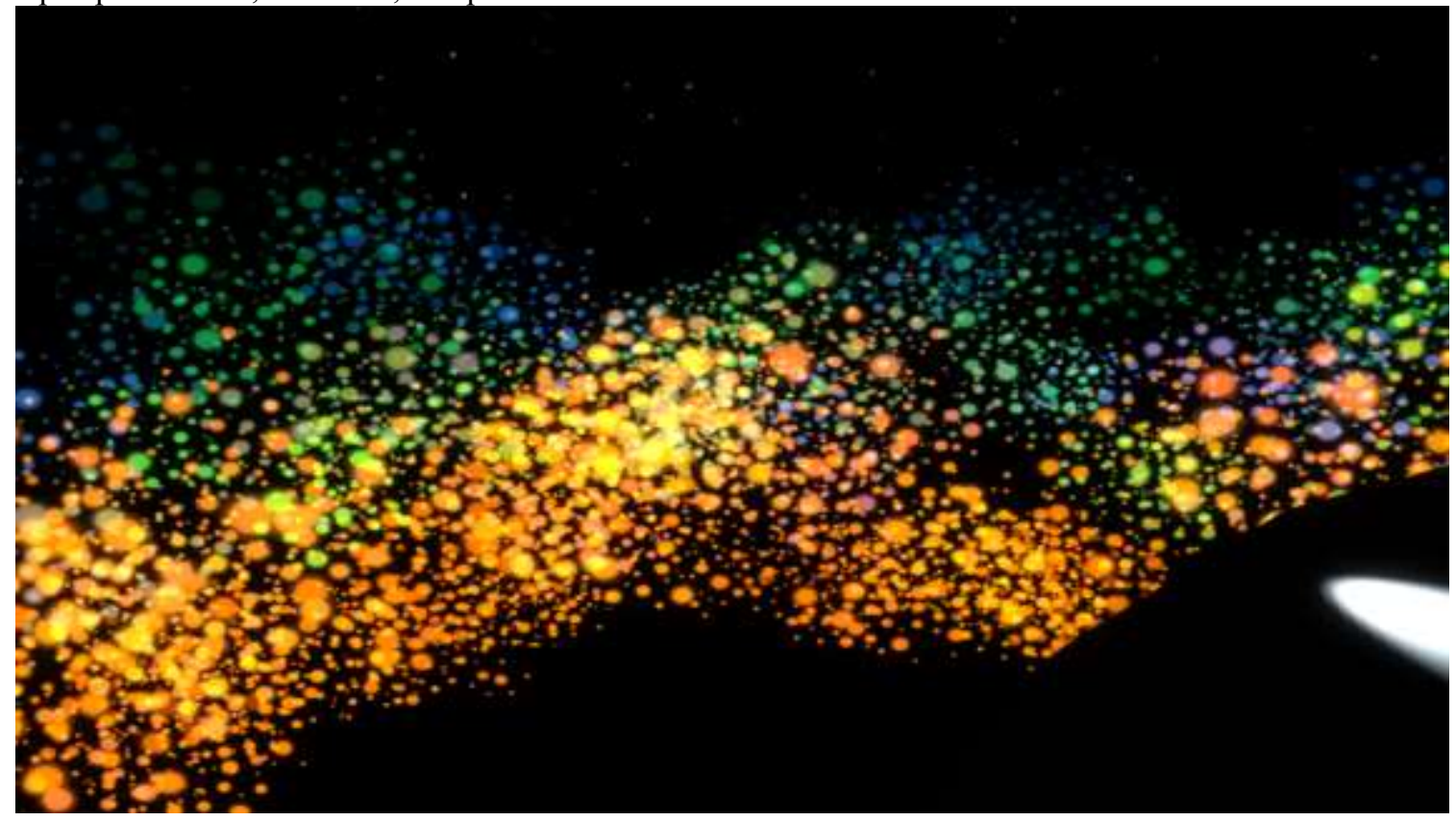

Данная локация создает впечатление того, что она появилась не по желанию рассказчика, а возникла в «игре» как следствие ошибки. Тема бесконечного замкнутого круга, запертости внутри «игры», в которую попали два этих персонажа звучит в игре постоянно, способствуя созданию эффекта слома четвертой стены.

Ирония над главным героем может заключаться и в отказе признать его умственные способности (потому что откуда они могут быть у человека, который счастлив от того, что год за годом нажимает кнопки по приказу свыше).

3 с англ. «Oh, no. No, it's to the right, my mistake!»

4 Please, no, Stanley, let me stay here! Don't take this from me! 


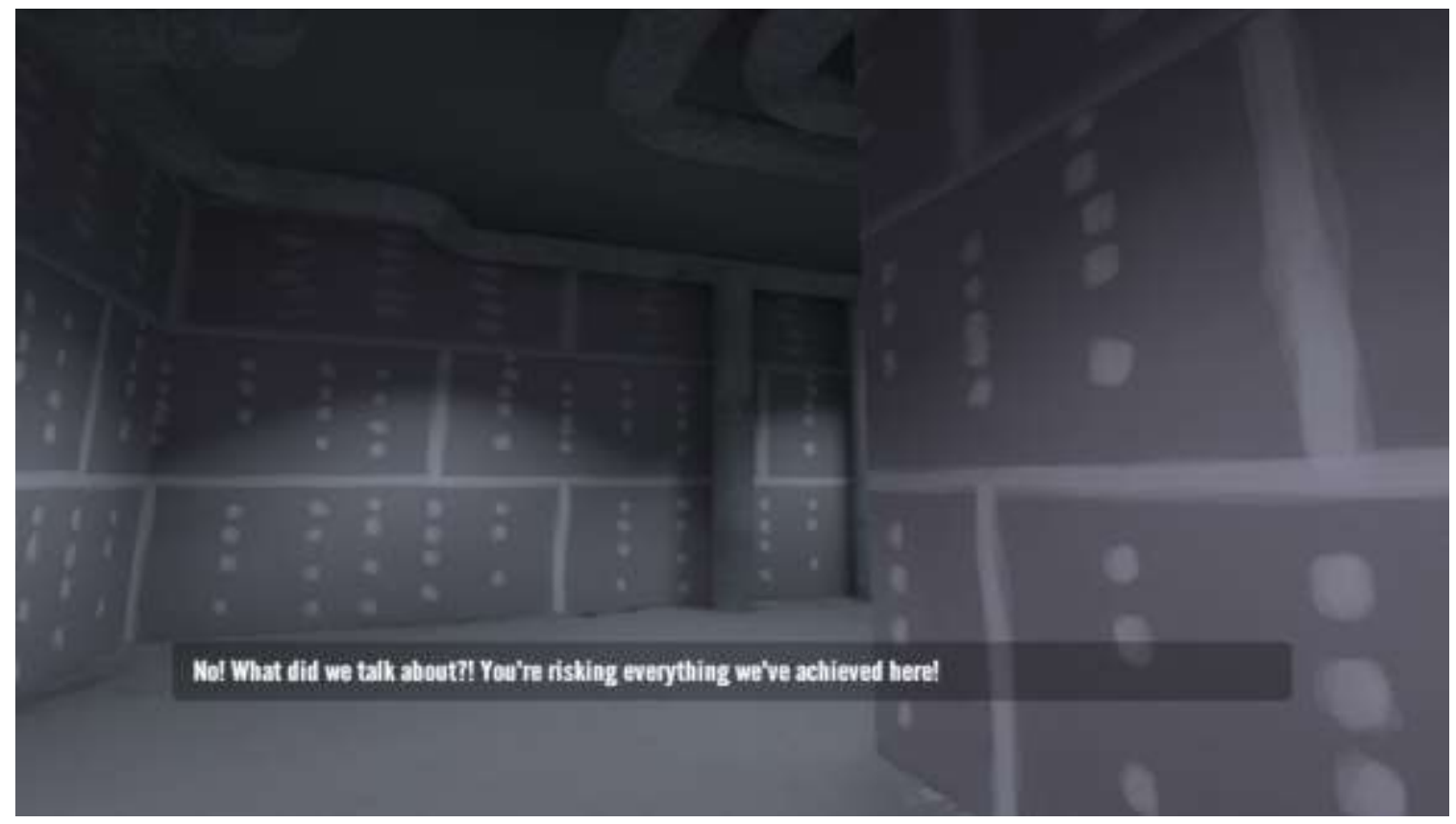

Рассказчик также позволяет себе откровенное глумление над Стенли: «Попался! Ой, ну ладно тебе! Неужели ты впрямь подумал, что у тебя действительно есть любящая жена?»[5]. (Речь идет о линии повествования, следующей за регулярным неподчинением игрока указаниям рассказчика, после чего рассказчик говорит Стенли, что ему следует подумать о «ней», через сцену Стенли стоит предположительно перед дверью своей квартиры и слышит женский голос, но дверь открывается и игрок-Стенли видит женский манекен).

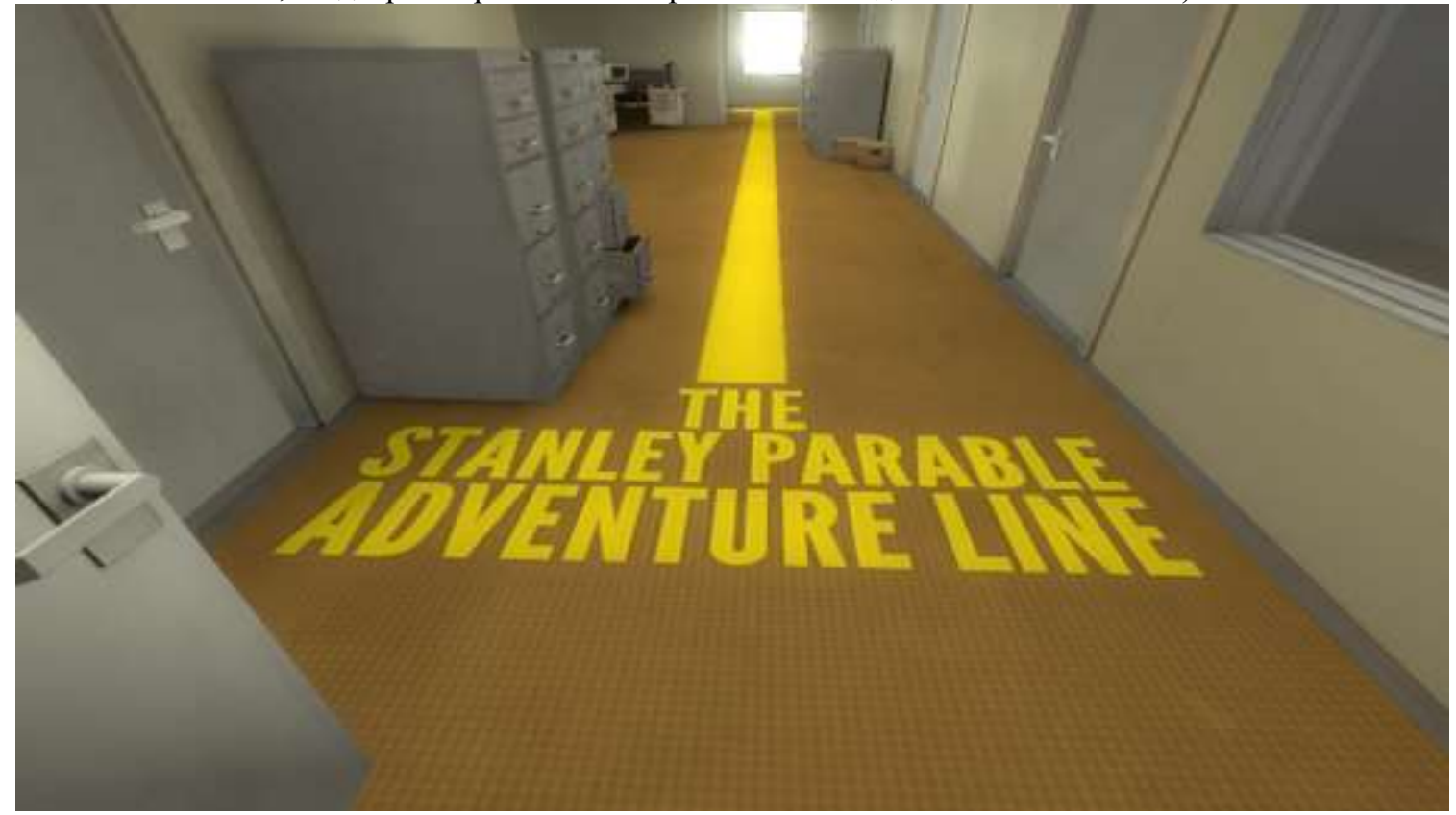

История может пойти не по тому пути, который «запланировал» рассказчик. И даже четкая крупная «Линия приключения Стенли Парабл! Просто следуй Линии! Это же так просто!»[6]), умудряется из прямой, превратиться в зигзаг, кривую, пролегающую по полу, стенам, потолку, закручивающуюся, по комнатам, вокруг столов и коробок, и раздваивающуюся в коридоре.

5 англ « Oh, come on. Did you actually think you had a loving wife?»

6 англ. «Parable Adventure Line ${ }^{\mathrm{TM}}$ ! Just follow The Line ${ }^{\mathrm{TM}}$; how simple is that!» 


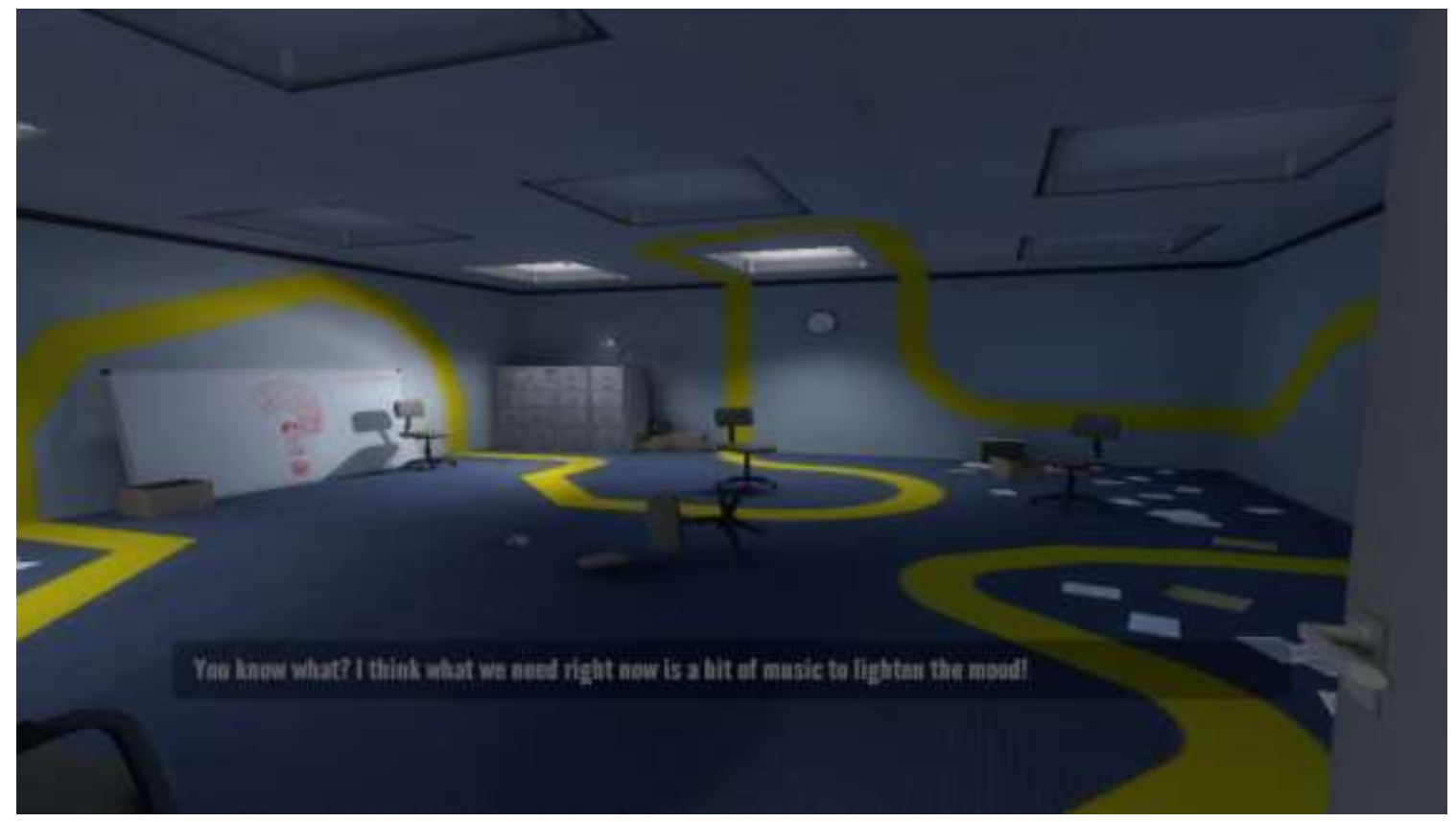

Окружение в The Stanley Parable играет роль инструмента рассказчика и подвижным материалом, подчеркивающим происходящие события. Оно меняется и практически полностью подчинено рассказчику. Сам же Стенли, производит одновременно впечатление пустой марионетки, так что диалог рассказчика происходит с игроком, и в то же время, Стенли как персонаж существует. В одной из концовок, игрока буквально принуждают к нажатию определенных кнопок на клавиатуре, после чего сюжет продолжает свое развитие. Эта часть одной из линий повествования словно призвана наказать игрока и Стенли за неподчинение рассказчику, за то, что они пытались вырваться из круга повествования, намерено не подчиняясь указаниям свыше (вместо левой двери, выбрать правую, вместо красной - синию, и т.д.), и чтобы показать Стенли, что он ничего не может сделать в повествовании без рассказчика, нарочито указывая на его подчиненное положение. Однако, если игрок находит линию, где персонаж попадает в музей, то там появляется второй персонаж-рассказчик. Женский голос говорит о непрерывном противостоянии двух персонажей, которые ненавидят и зависят друг от друга. По контексту становится понятно, что речь идет о Стенли и рассказчике, а повествование адресовано уже напрямую игроку. Музей разительно отличается от офиса, подсобных и заводских помещений, здесь очень чисто, почти стерильно, тихо, временами очень светло, присутствуют элементы подражающие классической архитектуре и подчеркнутый минимализм. Вместе они несут ощущение отчужденности от любых иных миров и спокойствие. Музей представляет собой ряд помещений, в которых собраны картины, концепт-арты, маленькие модели коридоров, перечисление наиболее ярких концовок и предметов игры.

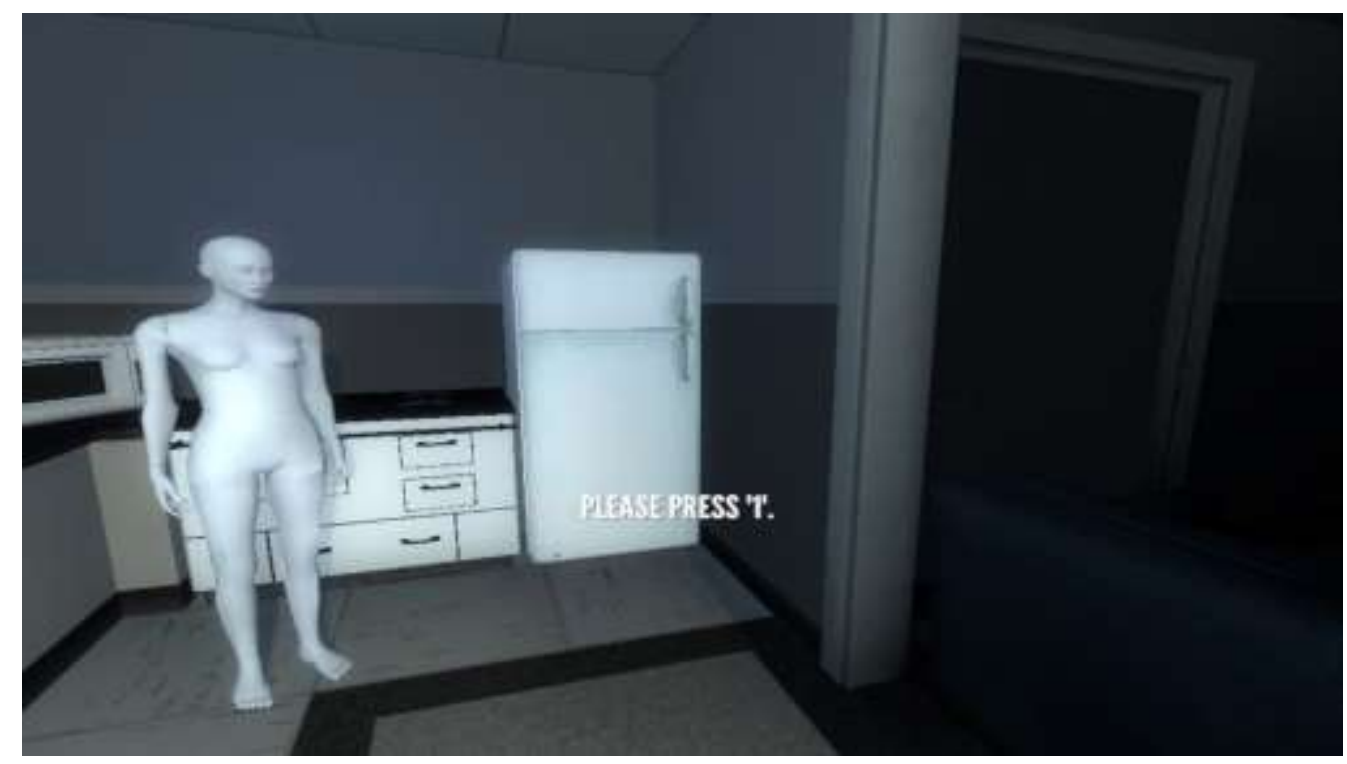




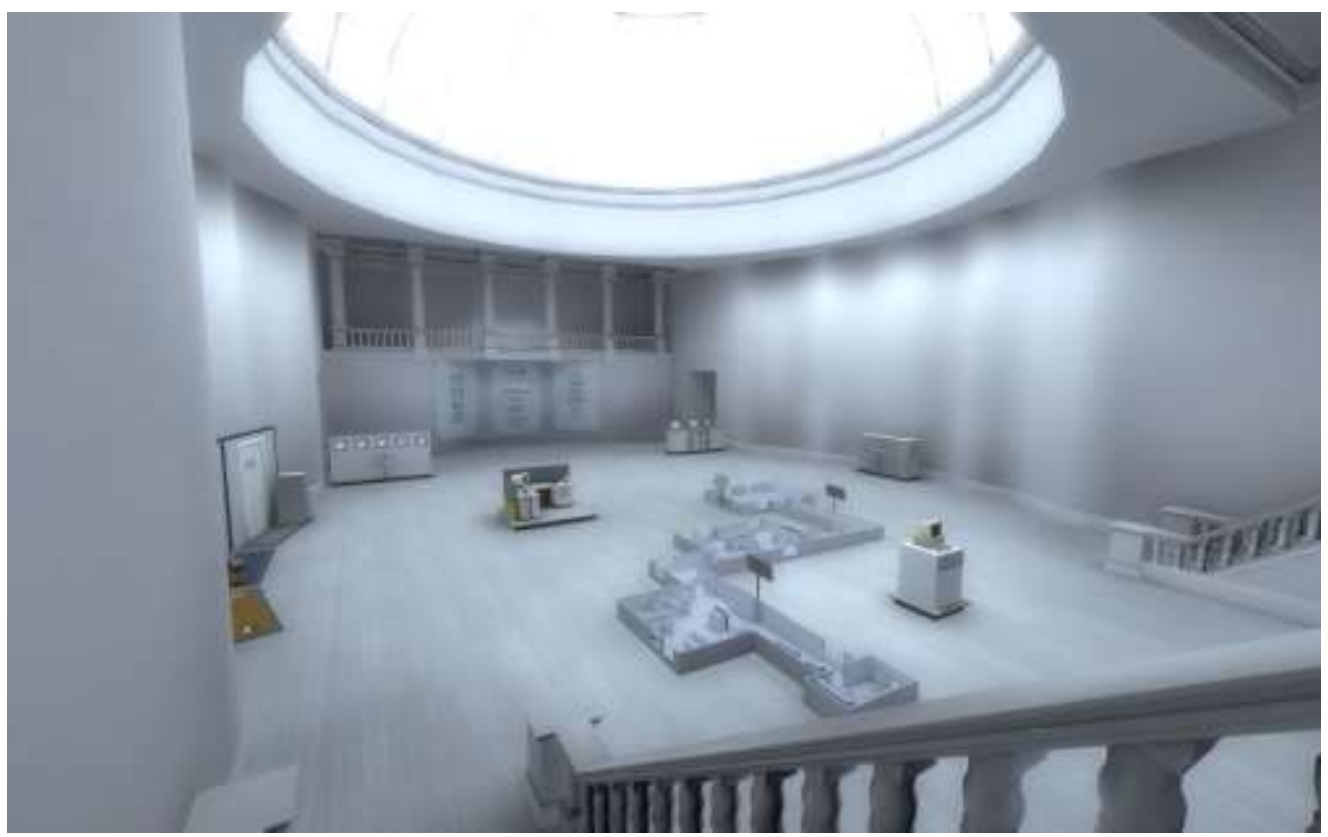

Перезагрузки и начало новых линий в игре происходят неразрывно от повествования. Игроку не всегда понятно, когда закончилась одна линия и начинается другая. К одной из наиболее характерных черт можно было бы отнести фразу: «Все его сослуживцы исчезли. Что бы это могло значить? Стэнли решил пойти в конференцзал; возможно, он просто пропустил объявление»[7] Однако, порой игра просто перезагружается на первую сцену в офисе, однако чуть видоизмененную, что создает ощущение непрерывности повествования и даже некоторой доли цикличности. Эта непрерывность и возможность «ослушаться» наставлений рассказчика способствует тому, что игроку кажется, что Стенли пытается вырваться из заданного свыше круга.

Герой продолжает сопротивляться и линии повествования множатся, меняются и раскрывают все больше вариаций происходящих событий. Причем не понятно, какие из этих событий действительно происходили, а какие нет. И был ли Стенли на самом деле, или все это плод фантазии рассказчика, застрявшего в своем маленьком, но в тоже время большом мире. Или же рассказчик является частью личности Стенли, как воплощение его горечи за свою жизнь и отвергнутого внутреннего ребенка, который живет в каждом из нас.

Таким образом, архитектура и дизайн находятся в непрерывной взаимосвязи с происходящими событиями, они подчеркивают их и являются эффективным и основополагающим инструментом для создания визуального образа произведения, его атмосферы. Но они не работали бы так сильно, если бы не повествование рассказчика, который как дирижер руководит всем происходящем в этом мире.

Конечно, история Стенли и рассказчика не была бы полной без диалога с самим игроком. И наиболее характерной интересной мыслью можно считать ту линию, где пройдя сквозь зарисовки разных игр (спаси младенца от огня, майнкрафт, портал) мы-Стенли оказываемся наедине с брошенными мыслями, незаконченными проектами, которые скорее всего не будут никогда закончены. И путешествуя сквозь проекты и их обломки игрок может четко осознать, что на долю успешных проектов на рынке приходятся десятки, а то и тысячи, неудачных, или попросту брошенных. Трио Рассказчика, Стенли и окружения в одной только игре, поведало игроку огромное количество историй, через которые прошел он сам. И такое путешествие не может не оставить после себя след. История The Stanley Parable по большей части не столько о героях, сколько об играх в целом и тенденциях в игровой индустрии, рассуждения о сюжетах в играх и роли выбора в них. Но данная мысль достойна развития в отдельной статье.

\section{Выводы}

В играх, как и в реальности, дизайн окружения, архитектура рассказывают о мире, являясь его неотъемлемой частью. Они отчасти берут на себя роль рассказчика, наглядно показывая особенности эпохи и быта обитателей.

Окружение может служит инструментом передачи атмосферы и замысла авторов, что также позволяет комбинировать привычные формы и создавать фантастические предметы и события.

Если сравнивать игры Assassin's Creed: Unity, Sublustrum, The Stanley Parable то мы увидим, что первая стремится к достоверной передаче духа эпохи, вторая - используя также исторические элементы, применяет их

7 Англ. «All of his co-workers were gone. What could it mean? Stanley decided to go to the meeting room; perhaps he had simply missed a memo.» 
иначе, третья же - делает окружение непосредственным участником повествования, формируя и направляя его в то или иное русло, одновременно позволяя игроку выбирать свой путь.

\section{Список литературы.}

1. Экскурсия по Парижу от создателей Assassin's Creed: Unity. Project Widow// 42.TUT.BY URL: https://42.tut.by/417063 (дата обращения 03.06. 2020)

2. Assassin's Creed: Unity поможет восстановить Собор Парижской Богоматери после пожара// Gameguru URL:

https://gameguru.ru/games/assassins_creed_unity/assassins_creed_unity_pomojet_vosstanovit_sobor_parijskoy_bogoma teri_posle_pojara/news.html (дата обращения 10.06.2020)

3. Демонстрация Project Widow// WayneDavies89 URL: https://www.youtube.com/watch?v=Vb3dGGVLq20 (дата обращения: 03.06.2020)

4. Почему не стоит изучать историю по Assassin's Creed, часть III. Париж и Лондон // xyz media URL: https://media-xyz.com/ru/articles/1419-pochemu-ne-stoit-izuchat-istoriiu-po-assassin (дата обращения: 18.03.2021).

5 Dialogue// Fandom URL: https://thestanleyparable.fandom.com/wiki/Dialogue (дата обращения 19.03.2021) 